\title{
The relationship between empathy and burnout - lessons for paramedics: a scoping review
}

This article was published in the following Dove Press journal:

Psychology Research and Behavior Management

Number of times this article has been viewed

\section{Brett Williams' \\ Rosalind Lau' \\ Emma Thornton' \\ Lauren S Olney ${ }^{2}$}

'Department of Community

Emergency Health and Paramedic

Practice, Faculty of Medicine,

Nursing and Health Sciences,

Monash University, Melbourne, VIC,

Australia; ${ }^{2} \mathrm{Clinical}$ and Community

Services Division, Ambulance Victoria,

Melbourne, VIC, Australia
Correspondence: Brett Williams Department of Community Emergency Health and Paramedic Practice, Monash University, Peninsula Campus, PO

Box 527, McMahons Road, Frankston, Melbourne, VIC 3199, Australia

Tel +6I 399044283

Fax +6I 399044168

Email brett.williams@monash.edu
Background: The concepts of empathy and burnout are critical for practicing paramedics and the profession. While there has been an increasing body of research on the relationship between empathy and burnout with physicians and nurses, surprisingly, no research has been undertaken with paramedics. The aim of this scoping review was to explore the relationship between empathy and burnout.

Method: A scoping review was performed based on Arskey and O'Malley's framework. Five databases were searched: CINAHL plus, EMBASE, MEDLINE, PsycINFO, and Scopus. Google Scholar was searched for gray literature. Two reviewers independently assessed eligibility and extracted the data.

Results: The initial search produced a yield of 1270 articles after removal of duplicates. All abstracts were screened for relevance, and 30 articles were selected for further screening. Twenty six articles were deemed relevant, of which there were 23 cross-sectional studies, two editorials, and one description article on the multidimensional aspect of burnout and empathy. The studies were conducted in Europe, USA, North America, and Asia. In most studies, there was an inverse correlation between empathy and emotional exhaustion and depersonalization but a positive correlation with personal accomplishment.

Conclusion: Although there seems to be a real relationship between empathy and burnout in physicians and nurses, the strength of the relationship differs to some extent depending on the samples and settings. Due to similarities between health professions, the relationship between empathy and burnout may also be relevant to the paramedic profession. Future paramedic research should focus on longitudinal studies to determine the factors that might influence empathy and burnout levels to provide a better understanding of these two key factors.

Keywords: burnout, empathy, nurse, physician, paramedic

\section{Introduction}

Prehospital emergency health care is a rapidly growing and evolving profession. Paramedics provide emergency and unscheduled medical assistance to people in the community with acute and chronic illnesses and injuries. ${ }^{1,2}$ Paramedics deal with a multitude of issues in their health care roles, for example, dealing with patients with poor health literacy, palliative care, family violence, poor living conditions of patients and alcohol and drug abuse situations. These can have an adverse impact on the mental well-being of paramedics, resulting in stress, burnout, posttraumatic stress disorders, and suicidal thoughts and behaviours. ${ }^{3-6}$ According to Ambulance Victoria, Australia, a National Coronial Information System report in June 2015 revealed that the suicide rate among paramedics is four times higher than the Victorian average and 
three times higher than other emergency workers (ie, police and fire fighters). ${ }^{7}$

Empathy is important in health care settings because it facilitates a positive relationship between health care professionals and patients. ${ }^{8,9}$ This positive relationship can buffer against professional burnout, ${ }^{10,11}$ which has become a major concern among health care professionals, including paramedics.

\section{Burnout}

Maslach, a pioneer in burnout theory, describes burnout as a sequence of three dimensions: 1) emotional exhaustion (EE); 2) depersonalization (DP); and 3) reduced personal accomplishment (PA). ${ }^{12}$ EE refers to high emotional demand leading to depletion of individuals' resources. DP refers to attempt to distance themselves emotionally from patients and colleagues. Reduced PA refers to a decreased sense of achievement and loss of self-esteem. Generally, burnout entails high levels of EE, a marked sense of DP, and low levels of PA. ${ }^{12}$ Health care professionals are frequently faced with long working hours, high patient load, time and resource constraints, and work and family life imbalance, ${ }^{13,14}$ resulting in burnout. Paramedics often face the same stressors. ${ }^{15,16}$

\section{Empathy}

Empathy is a complex, multidimensional concept consisting of both cognitive and affective (emotional) aspects. ${ }^{17}$ Affective empathy refers to experiencing the feelings of others, while cognitive empathy is the ability to understand the experiences and feelings of others and being able to relay that understanding back to them. Another key component of empathy, which distinguishes it from sympathy, is selfother differentiation, which is the ability to separate one's own emotions from those of the other person, ${ }^{11}$ which may improve objectivity and help to reduce anxiety and distress. In contrast, sympathy is about feeling "sorry" for someone rather than with someone. Empathy is widely accepted to be an important component of health care, as it leads to better patient outcomes and increased patient satisfaction. ${ }^{18}$ On the other hand, lower levels of empathy result in greater frequency of malpractice suits and decreased patient satisfaction. ${ }^{19}$ In a paramedic context, empathy not only improves patient outcomes and allows paramedics to perform their best but also improves psychological outcomes for families who have lost a loved one. ${ }^{20}$

\section{Relationship between empathy and burnout}

We were unable to locate any peer-reviewed literature examining the relationship between empathy and burnout within the paramedic profession. Therefore, given the paucity of paramedic literature, it is important to gain an understanding of the literature from other related health professions such as medicine and nursing. There are some professional similarities between these professions and paramedicine such as various clinical skills, exposure to unwell patients, emotionally demanding work, and the types of training they undergo. In addition, medicine and nursing have been key contributors to the development of paramedic curricula. As such, it is likely that results from these two professions may be relevant to the paramedic profession. A study found that cognitive empathy might have a protective role in burnout among Canadian primary care general practitioners (GPs). ${ }^{21}$ Another study on GPs found high empathy to be significantly associated with low burnout in Spain. ${ }^{22}$ Moreover, a study on Swedish district nurses found the lower the burnout score, the higher the empathy score. ${ }^{23}$ Another study on nurses in Korea found nurses with lower cognitive empathy were more likely to experience burnout. ${ }^{24}$ Therefore, the aim of this scoping review was to explore the relationship between empathy and burnout on physicians and nurses. These findings will then be used to inform and guide the next steps in addressing this critical area of health and well-being research for the paramedic profession.

Ethics committee approval was not required due to the nature of a scoping study.

\section{Methods}

The aim of a scoping review is to collate information from various sources, both peer- and non-peer-reviewed articles to provide a broad understanding of a topic. This scoping review was guided by Arksey and O’Malley six stages methodology. ${ }^{25}$ The stages are:

1. Identify the research question

2. Identify relevant studies

3. Study selection

4. Charting the data

5. Collating, summarizing, and reporting results

6. Expert consultation (optional)

\section{Stage I: Identify research question}

Empathy in health care settings is important because it enhances positive patient outcomes and satisfaction. ${ }^{9,17,26}$ Empathetic communication facilitates positive relationship between patients and the health care professionals. ${ }^{8,9}$ Furthermore, this relationship has a positive effect on health care professionals and can buffer against professional burnout. ${ }^{10,11}$

The demands of the job may cause stress, with work overload, and time and resource constraints being predictors of 
professional burnout. ${ }^{27}$ Given the prominent issue of empathy and burnout particularly in emergency health care and the evident effects of emotional disconnection, the following research question was chosen to guide the scoping review: Is there a relationship between paramedic empathy and burnout?

\section{Stage 2: Identify relevant studies}

Five databases were searched for relevant articles: CINAHL plus, EMBASE, Ovid MEDLINE, PsycINFO, and Scopus. Google Scholar was also searched for gray literature. There were no restrictions on date published or peer-review status. Initial search terms used included "paramedic*," "emergency medical technician*," "ambulance*," "empathy*," "burnout," and "job satisfaction." However, as no relevant studies were found in this initial search, the search parameters were expanded to include physicians and nurses given their job functions are the closest to paramedicine in terms of patient contact situations, long and irregular working hours, and exposure to distressing circumstances. Search terms added in this stage included "doctor*," "nurse*," and "physician*."

\section{Stage 3: Study selection}

Two reviewers independently assessed eligibility and extracted the data. The initial search produced 1270 articles after removal of duplicates. All abstracts were screened for relevance, and 30 articles were selected for the full-text screening. All 30 full texts were read and reviewed against the following criteria:

1. Articles must examine the relationship between empathy and burnout

2. Articles must be on the physicians and/or nurses

3. Articles must have the full-text available in English

Four articles were excluded at this stage due to irrelevance, leaving 26 articles to be included in this review.

\section{Stage 4: Charting the data}

The included studies are presented with summary in Table 1.

\section{Stage 5: Collating, summarizing, and reporting the results}

Twenty six articles that discussed the association between empathy and burnout for physicians and nurses were found. Twenty three were original studies, while two were editorials and one descriptive article. Eleven articles focused on nurses, five were on physicians, and five on both nurses and physicians. Another five were on medical students or residents only. 

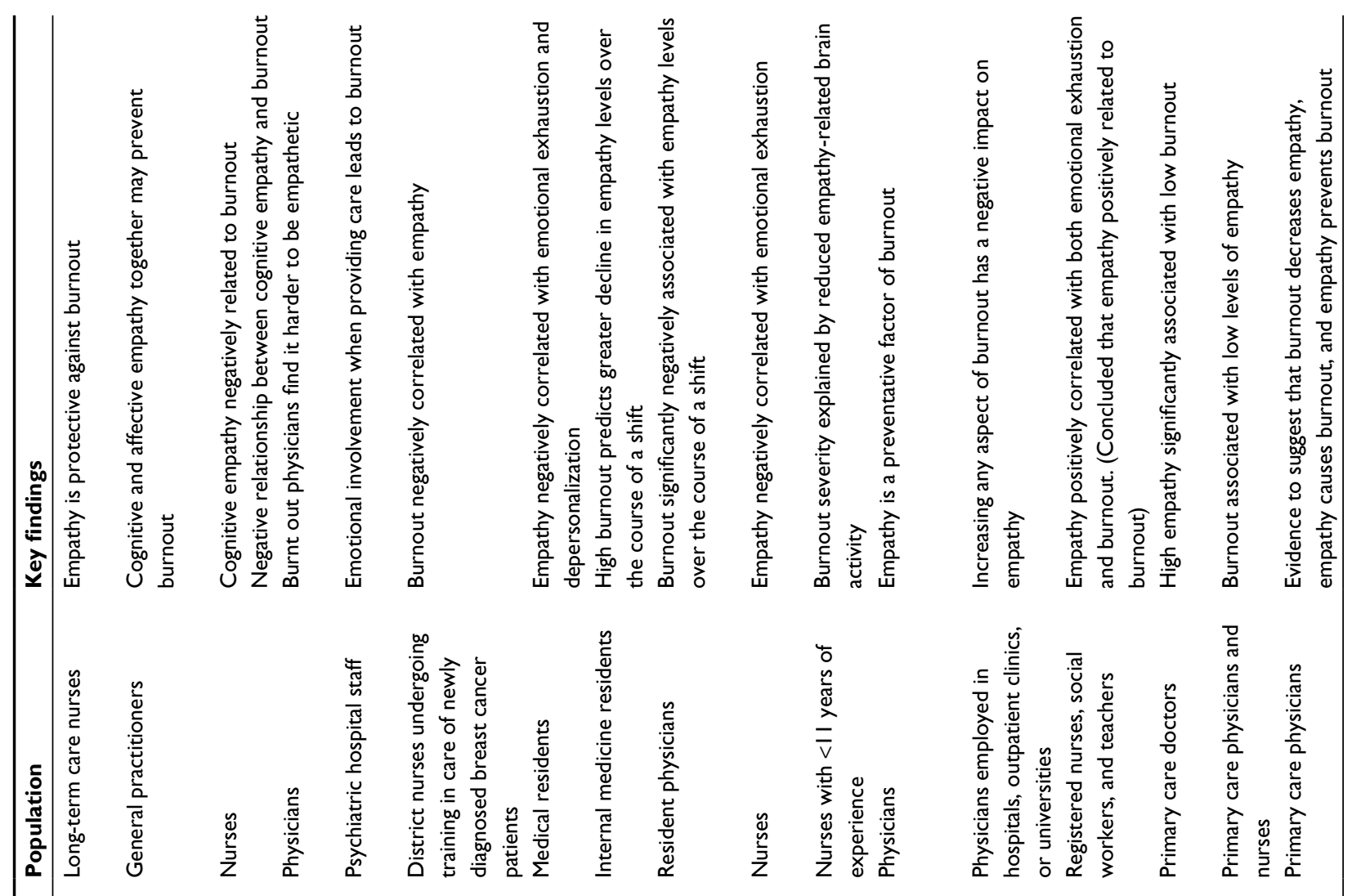

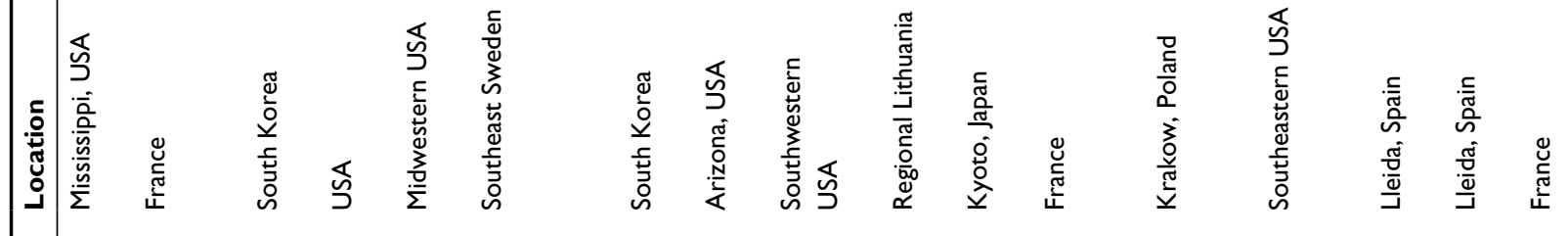

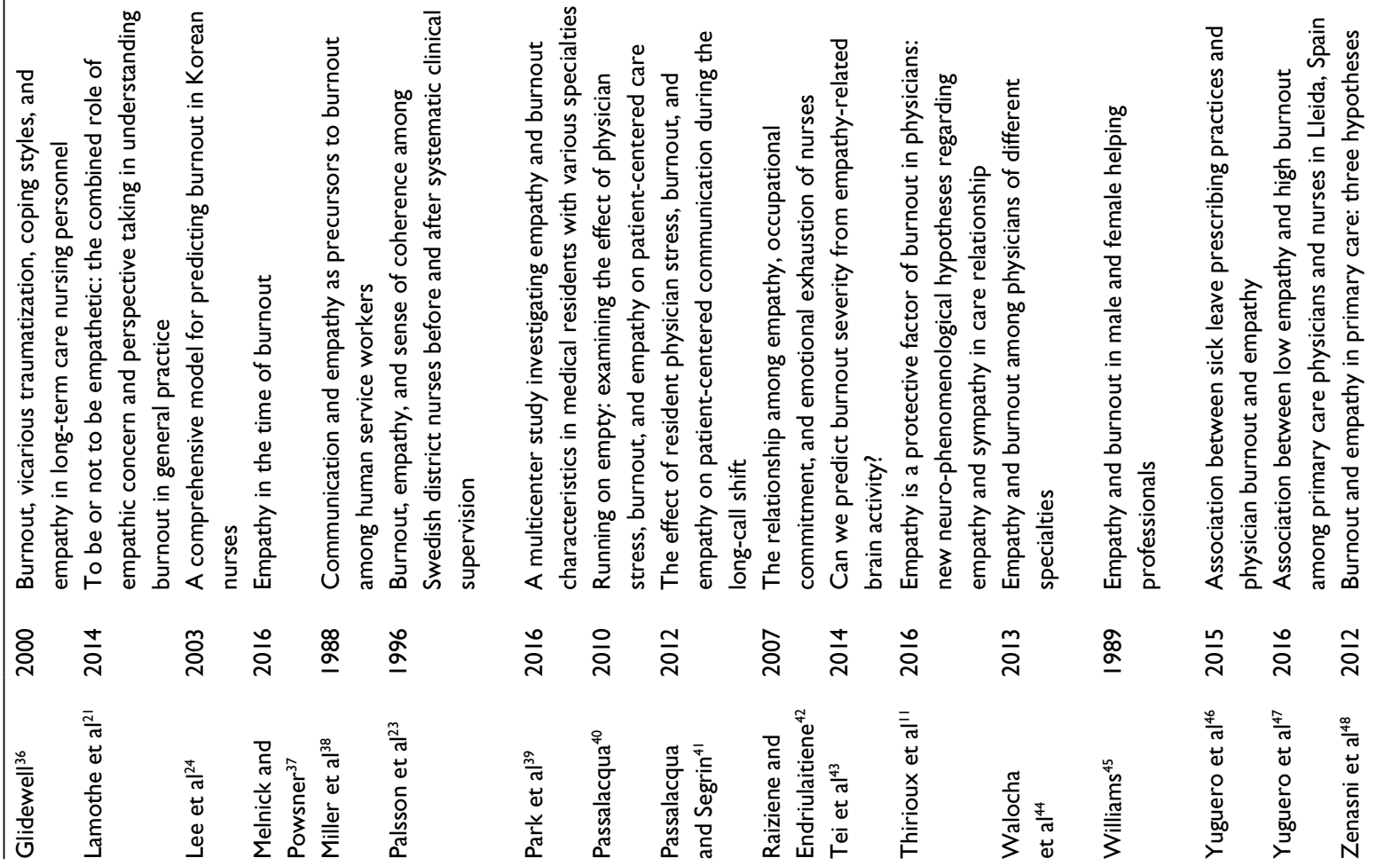


The key themes identified in the articles were as follows:

1. There is a negative relationship between empathy and burnout, that is, the less empathetic a physician or nurse is, the more likely they are to be burned out, and the more severely burned out they are likely to be. The vast majority of articles identified this correlation.

2. Three of the studies concluded that lack of empathy could lead to burnout.

3. Six studies claimed that burnout is a contributing factor to low levels of empathy.

4. Five studies found that empathy was a protective factor against burnout.

\section{Discussion}

Of the 26 articles reviewed, 22 were original studies. ${ }^{6,21,23,24,28-36,38-45,47}$ Although most studies showed a negative correlation between empathy and burnout, it is interesting to note that the strength of the relationships differed depending on the samples and settings. Those studies were conducted in Europe, USA, North America, and Asia. Two were editorials $^{37,48}$ and one ${ }^{11}$ was a description paper on the multidimensional features of empathy and burnout and the differences between empathy and sympathy to give a better understanding of the relationship between empathy and burnout.

\section{Relationship between empathy and burnout}

\section{Nurses}

Astrom et $\mathrm{al}^{6}$ studied 358 different Swedish nursing staff caring for patients with dementia in a nursing home, general long-term care clinic, and psychogeriatric clinic to compare empathy, burnout, and attitude levels among different nursing staff and to examine the relationships between the three concepts. They found a weak negative correlation $(r=-0.19)$ between burnout ${ }^{49}$ and empathy. ${ }^{50}$ Baxter $^{29}$ surveyed 124 American nurses working in an acute care hospital in New Hampshire to determine the empathy and burnout levels. Empathy was measured with the Barrett-Lennard Relationship Inventory (BLRI), ${ }^{51}$ and the Maslach Burnout Inventory (MBI) was used to measure burnout in three domains: emotional exhaustion (MBI-EE), depersonalization (MBI-DP), and reduced personal accomplishment (MBI-PA). They found a statistically significant inverse correlation $(r=-0.32$, $p<0.0001)$ between empathy and DP, but a positive correlation $(r=0.20, p=0.021)$ with PA.

Ferri et $\mathrm{al}^{33}$ evaluated the relationship between empathy and burnout in 97 Italian nursing students and 162 nurses.
They found a strong negative correlation between EE and emotional empathy measured by the Balanced Emotional Empathy Scale (BEES) $)^{52,53}$ for both students $(r=-0.30$, $p<0.002)$ and nurses $(r=-0.24, p<0.002)$. Whereas, MBIPA showed a strong positive correlation with the BEES mean total scores in students $(r=0.31, p<0.002)$ and nurses $(r=-0.26, p<0.001)$. MBI-DP was not associated with the BEES mean total scores (values not reported). The authors concluded that a high degree of empathy can be "protective against the development of burnout" $" 33$ (p. 111).

\section{Physicians}

Fulop et $\mathrm{al}^{34}$ investigated burnout in psychiatry residents and medical specialists and examined the relationship between emotional involvement, communicational skills, and burnout symptoms. MBI was used to measure burnout, and empathy was assessed with the Interpersonal Reactivity Index (IRI), the latter evaluating four domains of empathy. They found a statistically significant positive correlation between MBI-EE and the IRI Personal Distress domain ${ }^{54}(r=0.36, p<0.001)$, but negative correlations between MBI-DP and IRI Perspective Taking domain $(r=-0.32, p<0.001)$ and IRI Empathetic Concern domain $(r=-0.38, p<0.001)$.

The Jefferson Scale of Empathy Health Professional version (JSE-HP) was developed for specific use with health professionals. ${ }^{55}$ Park et al ${ }^{39}$ used the Korean edition of this scale along with the MBI to assess the relationship between empathy and burnout in 317 Korean medical residents. There were statistically significant negative correlations with MBI-EE $(r=-0.27, p<0.001)$ and MBI-DP $(r=-0.44$, $p<0.001)$ but a positive correlation with MBI-PA $(r=0.50$, $p<0.001)$. A similar pattern was observed in separate analyses of the people-oriented specialties (MBI-EE, $r=-0.31$; MBI-DP, $r=-0.51$; MBI-PA, $r=0.47)$ and technology-oriented specialties (MBI-EE, $r=-0.22$; MBI-DP, $r=-0.36$; MBIPA, $r=0.56)$. People-oriented specialties included internal medicine, obstetrics and gynecology, emergency medicine, and psychiatry. Technology-oriented specialties included anesthesiology, neurosurgery, surgery, and radiology. This was a significant result as it demonstrated that correlation exists even in residents at the beginning of their careers, not just in more experienced practitioners, and that those with less empathic capabilities are more vulnerable to burnout at the start of their careers. Such results and study design would be worthy of replicating with paramedic cohorts and provide opportunities for researchers to undertake such research.

Walocha et $\mathrm{al}^{44}$ assessed the level of empathy and burnout among 71 Polish physicians of different specialization. They 
found a statistically significant difference between surgical and non-surgical physicians in the level of MBI-EE $(p=0.03)$. Non-surgical specialists had higher BMI-EE. It is interesting to note that they found a statistically significant inverse correlation between MBI-PA and empathy (measured with the Emotional Empathy Scale $(\mathrm{EES})^{56}(r=-0.23, p<0.05)$. This finding was not supported by other studies. ${ }^{29,39}$ One possible explanation may be the use of different empathy measures. Walocha et $\mathrm{al}^{44}$ used the EES, ${ }^{56}$ while Baxter $^{29}$ used the BLRI $^{57}$ and Park et $\mathrm{al}^{39}$ used the JSE-HP. ${ }^{55}$ They also found a negative correlation between the level of empathy (according to the Thematic Apperception Test) and MBI-EE ( $r=-0.30$, $p<0.05)$ and MBI-DP $(r=-0.39, p<0.01)$ and no positive correlation with MBI-PA ( $r=0.14, p$-value was not reported).

\section{Nurses and physicians}

Additionally, Yuguero et $\mathrm{al}^{47}$ studied the association between empathy and burnout in 136 Spanish primary care physicians and 131 family nurses. They found a significant association between empathy and burnout in both the groups; for the nurses $(p=0.011)$ and for the physicians $(p=0.001)$. However, they found no significant differences between physicians and nurses in empathy and burnout. Although there is evidence to suggest a negative relationship between empathy and burnout, it remains unclear as to how they interact. Three possibilities are discussed below.

\section{Low empathy leading to higher burnout}

Three studies identified that low empathy could be a contributing factor for high burnout. Lee et $\mathrm{al}^{24}$ examined individual characteristics, job stress, and personal resource to identify significant predictors of burnout of 178 Korean nurses. For MBI-DP, they found 24\% variance (adjusted $R^{2}=0.19$ ) was explained by individual characteristics, job stress, and personal resources. Among personal resources, cognitive empathy was a significant predictor, accounted for $5 \%$ of the variance. For MBI-PA, 35\% variance (adjusted $R^{2}=0.31$ ) was explained by the proposed predictor variables in the study. Hence, the authors suggested that increasing cognitive empathy levels may be one way to reduce burnout.

In 2014 Tei et al, ${ }^{43}$ explored two models of burnout; the "compassion fatigue theory" which proposes that too much empathy is associated with burnout and the "emotional dissonance theory" which proposes that a low level of emotional regulation may produce a disparity between experienced and expressed emotions. ${ }^{43}$ The relationship between burnout severity scores and psychological measures of empathic disposition (measured by the IRI), emotional dissonance (measured by the Emotion Work Requirements Scale, EWRS), and alexithymia (difficulty in identifying and experiencing ones' emotions ${ }^{58}$ and measured by the Toronto Alexithymia Scale, TAS) were undertaken among 25 nurses. They found statistically positive significant relationships between MBI-EE and IRI-PT ( $r=0.50, p=0.010$ ), EWRS (hide negative emotion) $(r=0.430, p<0.032)$, TAS-20 (difficulty in identifying feelings $(r=0.63, p<0.001)$. The positive correlation between burnout severity and emotional dissonance was no longer significant when alexithymia scores were covaried out $(\mathrm{r}=0.26, p=0.21)$, suggesting a link between burnout, emotional dissonance, and alexithymia. The positive correlation between burnout severity and empathy remained significant when alexithymia scores were covaried out ( $r=0.46$, $p=0.02$ ), supporting both theories of "compassion fatigue" and "emotional dissonance."

Lamothe et $\mathrm{al}^{21}$ studied 294 French GPs. They found when predicting burnout using sympathy, empathy, and their interaction as predictors, each of the predictors was uniquely associated with the outcome; with lower empathy scores predicting higher burnout (model adjusted for marital status). Higher sympathy $(\beta=-0.17, p<0.05)$ and higher empathy $(\beta=-0.21, p<0.001)$ predicted lower burnout. The interaction term was also significant $(\beta=0.11, p<0.05)$ suggesting that empathy and sympathy may interact to protect against burnout. The total model explained $10 \%$ of the variance of burnout $\left(R^{2}=0.08\right.$ without controls). Hence, the importance of training health care professionals in techniques of emotion regulation is emphasized. These findings provide important background for future paramedic research.

\section{Higher burnout leading to lower empathy}

Six articles implied that high burnout might result in low empathy. ${ }^{6,30,33,37,41,44}$ Many health care workers are subject to work overload, which Astrom et al ${ }^{6}$ recognized as a significant cause of burnout. This may lead to irritation and the feeling of being "weighed down" and emotionally exhausted, which can affect a physician's ability and motivation to empathize with their patients. On the other hand, Ferri et $\mathrm{al}^{33}$ found that DP was more related to emotional disconnection from patients, stating "depersonalisation does not permit a therapeutic relationship." Ferri et al ${ }^{33}$ suggested that the decline in empathy observed in a burnout of nurses may be a defence mechanism against human suffering; subconsciously attempting to protect themselves by feeling less empathic towards the patients. Bradham ${ }^{30}$ also found that nurses lost the ability to empathize with their patients if they are burnt out. Passalacqua and Segrin ${ }^{41}$ found that during the latter half of 
physicians' long shift work, they suffered from burnout due to sleep deprivation and work overload resulting in significant reduction of empathy toward their patents.

\section{Empathy as a protective factor}

Six articles ${ }^{11,21,33,34,36,48}$ showed that empathy could be a protective factor against burnout. According to Thirioux et al, ${ }^{11}$ a key characteristic of empathy is self-other distinction, that is, putting yourself in the patients' shoes but at the same time recognizing that your emotions are separated from those of the patients. This self-other distinction helps to prevent burnout as it reduces the EE associated with negative emotions. It also makes health care professionals more "immune" to DP, ${ }^{11}$ as the two concepts are in polar opposition. However, the biggest effect of empathy on burnout seems to be an increase in personal achievement. It is well known that empathic physicians and nurses provide a higher quality of care, ${ }^{48}$ and this "generates a greater professional satisfaction." 11

\section{Application to the paramedic profession}

Although this scoping review explored the relationship between burnout and empathy on physicians and nurses, it is conceivable that some of the findings may also be relevant to paramedics. Paramedics experience many of the same job stressors as nurses and physicians, and burnout is equally well known to affect paramedics as their in-hospital counterparts. ${ }^{16}$ Empathy is a central component in effective communication and maintaining therapeutic communication between paramedics and patients. ${ }^{30}$ Paramedics who are constantly exposed to highly distressing situations (eg, illnesses and deaths) may be particularly vulnerable to develop stress and compassion fatigue or burnout, unless they are effective in controlling their capacity to empathise.$^{59}$ Melnick and Powsner ${ }^{37}$ pointed out that to increase physician-patient relationship, a health care system needs to invest more toward health care providers. It will lead to a detailed study to determine if these strategies are applicable to the paramedic profession. Those responsible for research, policy development, and educators of paramedics can use these findings described in other providers in developing future interventions in paramedics.

\section{Limitations and future research}

The review was on the physicians and the nurses and not on paramedics because of lack of peer-reviewed literature on paramedics. Nevertheless, the findings from this review are likely to be applicable to paramedics. Although there is an association between empathy and burnout in many health care professionals, it is unclear as to what degree of burnout needs to occur before it leads to low empathy or degree of empathy that needs to exist to protect against burnout. Due to the lack of paramedic-specific information, it is important to learn lessons from other associated professions. This information may inform and generate new paramedic-orientated research in the area of empathy and burnout. Future areas of research should focus on longitudinal studies in paramedics to determine the factors that might influence empathy and burnout levels to provide a better understanding of the two key factors. Suggestions for mixed methodology designs are also warranted for future research studies to add the component of qualitative insight into the mechanisms and response to burnout in paramedics. Additional studies should examine what levels of educational preparation regarding stress and empathy are provided to student paramedics and paramedics during their studies, as well as review the impact of ambulance service organizational culture in the process of mitigating and/or treating burnout effectively in this population.

\section{Conclusion}

Although there seems to be a real relationship between empathy and burnout among nurses and physicians, the characteristics of the relationship differ to some extent depending on the samples and settings. Due to cognitive and clinical similarities between health professions, the relationship between empathy and burnout may also be relevant to the paramedic profession. Future paramedic research should focus on longitudinal studies to determine the factors that might influence empathy and burnout levels to provide a better understanding of these two elements.

\section{Disclosure}

The authors report no conflicts of interest in this work.

\section{References}

1. Sterud T, Ekeberg $\varnothing$, Hem E. Health status in the ambulance services: a systematic review. BMC Health Serv Res. 2006;6:82.

2. Regehr C, Goldberg G, Hughes J. Exposure to human tragedy, empathy, and trauma in ambulance paramedics. Am J Orthopsychiatry. 2002;72(4):505-513.

3. Sterud T, Hem E, Lau B, Ekeberg O. Suicidal ideation and suicide attempts in a nationwide sample of operational Norwegian ambulance personnel. J Occup Health. 2008;50(5):406-414.

4. Johnson S, Cooper C, Cartwright S, Donald I, Taylor P, Millet C. The experience of work-related stress across occupations. J Manag Psychol. 2005;20(2):178-187.

5. Stanley I, Hom M, Joiner T. A systematic review of suicidal thoughts and behaviors among police officers, firefighters, EMTs, and paramedics. Clin Psychol Rev. 2016;44:25-44.

6. Astrom S, Nilsson M, Norberg A, Winblad B. Empathy, experience of burnout and attitudes towards demented patients among nursing staff in geriatric care. J Adv Nurs. 1990;15(11):1236-1244. 
7. Ambulance Victoria. Mental health and wellbeing strategy 2016-19; 2016. Available from: https://s3-ap-southeast-2.amazonaws.com/prod. assets.ambulance.vic.gov.au/wp-content/uploads/2016/10/ambulancevictoria-mental-health-strategy-2016-19.pdf. Accessed Feb 13, 2017.

8. McMillan L, Shannon D. Psychometric analysis of the JSPE nursing student version R: comparison of senior BSN students and medical students attitudes toward empathy in patient care. ISRN Nurs. 2011;2011(1-7):1-7.

9. Clark A. Empathy: an integral model in the counseling process $J$ Counsel Development. 2010;88(3):348-356.

10. Hojat M, Vergare M, Isenberg G, Cohen M, Spandorfer J. Underlying construct of empathy, optimism, and burnout in medical students. Int J Med Educ. 2015;6:12-16.

11. Thirioux B, Birault F, Jaafari N. Empathy is a protective factor of burnout in physicians: new neuro-phenomenological hypotheses regarding empathy and sympathy in care relationship. Front Psychol. 2016;7:1-11, Article 763.

12. Maslach C. What we have learned about burnout and health. Psychol Health. 2001;16:607-611.

13. Kalicinska M, Chylinska J, Wilczek-Rózyczka E. Professional burnout and social support in the workplace among hospice nurses and midwives in Poland. Int J Nurs Pract. 2012;18:595-603.

14. Meier D, Beresford L. Preventing burnout. J Palliat Med. 2006;9(5): $1045-1050$

15. Nirel N, Goldwag R, Feigenberg Z, Abadi D, Halpern P. Stress, work overload, burnout, and satisfaction among paramedics in Israel. Prehosp Disaster Med. 2008;23(6):537-546.

16. Stassen W, Van Nugteren B, Stein C. Burnout among advanced life support paramedics in Johannesburg, South Africa. Emerg Med J. 2013;30:331-333.

17. Hojat M, Louis D, Markham F, Wender R, Rabinowitz C, Gonnella J. Physicians' empathy and clinical outcomes for diabetic patients. Acad Med. 2011;86(3):359-364.

18. Derksen F, Bensing J, Lagro-Janssen A. Effectiveness of empathy in general practice: a systematic review. Br J Gen Pract. 2013;63(606):76-84.

19. Haslam N. Humanizing medical practice: the role of empathy. Med $J$ Aust. 2007;187(7):381-382.

20. Williams B, Boyle M, Fielder C. Empathetic attitudes of undergraduate paramedic and nursing students towards four medical conditions: a three-year longitudinal study. Nurse Educ Today. 2015;35(2):e14-e18.

21. Lamothe M, Boujut E, Zenasni F, Sultan S. To be or not to be empathic: the combined role of empathic concern and perspective taking in understanding burnout in general practice. BMC Fam Pract. 2014;15:15.

22. Yuguero O, Esquerda M, Mora J, Soler-González J. Association between sick leave prescribing practices and physician burnout and empathy. PLoS One. 2015;10:e0133379.

23. Palsson M, Hallberg I, Norberg A, Bjorvell H. Burnout, empathy and sense of coherence among Swedish district nurses before and after systematic clinical supervision. Scand J Caring Sci. 1996;10(1):19-26.

24. Lee H, Song R, Cho YS, Lee GZ, Daly B. A comprehensive model for predicting burnout in Korean nurses. J Adv Nurs. 2003;44(5):534-545.

25. Arksey H, O’Malley L. Scoping studies: towards a methodological framework. Int J Soc Res Methodol. 2005;8:19-32.

26. Del Canale S, Louis D, Maio V, et al. The relationship between physician empathy and disease complications: an empirical study of primary care physicians and their diabetic patients in Parma, Italy. Acad Med. 2012;87(9):1243-1249.

27. Schaufeli W, Buunk B. Burnout: an overview of 25 years of research and theorizing. In: Schabracq MJ, Winnubst JAM, Cooper CL, editors. The Handbook of Work and Health Psychology. 2nd ed. West Susses, England: Wiley; 2003:383-429.

28. Astrom S, Nilsson M, Norberg A, Sandman P, Winblad B. Staff burnout in dementia care: relations to empathy and attitudes. Int J Nurs Stud. 1991;28(1):65-75

29. Baxter DE. Empathy: Its role in nursing burnout [dissertation]. Nashville: Peabody College for Teachers of Vanderbilt University; 1992. Available from: http://search.ebscohost.com.ezproxy.liv.ac.uk/login.asp $\mathrm{x}$ ?direct=true $\& \mathrm{db}=\mathrm{jlh} \& \mathrm{AN}=1994198441 \&$ site=ehost-live \&scope=site . Accessed February 18, 2017.
30. Bradham KM. Empathy and Burnout in Nurses [dissertation]. Chicago, IL: Faculty of the Institute for Clinical Social Work; 2008.

31. Brazeau CMLR, Schroeder R, Rovi S, Boyd L. Relationships between medical student burnout, empathy, and professionalism climate. Acad Med. 2010;85(10 Suppl):S33-S36.

32. Duarte J, Pinto-Gouveia J, Cruz B. Relationships between nurses' empathy, self-compassion and dimensions of professional quality of life: a cross-sectional study. Int J Nurs Stud. 2016;60:1-11.

33. Ferri P, Guerra E, Marcheselli L, Cunico L, di Lorenzo R. Empathy and burnout: an analytic cross-sectional study among nurses and nursing students. Acta Biomedica. 2015;86:104-115.

34. Fulop E, Devecsery A, Hausz K, Kovacs Z, Csabai M. Relationship between empathy and burnout among psychiatric residents. New Med. 2011; 4:143-147.

35. Garrett C. Stress, Coping, Empathy, Secondary Traumatic Stress and Burnout in Healthcare Providers Working with HIV-Infected Individuals [dissertation]. New York: Ehrenkranz School of Social Work; 1999.

36. Glidewell R. Burnout, Vicarious Traumatization, Coping Styles, and Empathy in Long-Term Care Nursing Personnel [dissertation]. Southern Mississippi: Graduate School; 2000.

37. Melnick ER, Powsner SM. Empathy in the time of burnout. Mayo Clin Proc. 2016;91(12):1678-1679.

38. Miller K, Stiff J, Ellis B. Communication and empathy as precursors to burnout among human service workers. Commun Monogr. 1988;55(3):250-265.

39. Park C, Lee YJ, Hong M, et al. A multicenter study investigating empathy and burnout characteristics in medical residents with various specialties. J Korean Med Sci. 2016;31(4):590-597.

40. Passalacqua S. Running on Empty: Examining the Effect of Physician Stress, Burnout, and Empathy on Patient-Centered Communication During the Long-Call Shift [dissertation]. Arizona: The University of Arizona; 2010.

41. Passalacqua S, Segrin C. The effect of resident physician stress, burnout, and empathy on patient-centered communication during the long-call shift. Health Commun. 2012;27:449-456.

42. Raiziene S, Endriulaitiene A. The relations among empathy, occupational commitment, and emotional exhaustion of nurses. Medicina (Kaunas). 2007;43(5):425-431.

43. Tei S, Becker C, Kawada R, et al. Can we predict burnout severity from empathy-related brain activity? Transl Psychiatry. 2014;4(6):e393.

44. Walocha E, Tomaszewski K, Wilczek-Ruzyczka E, Walocha J. Empathy and burnout among physicians of different specialties. Folia Medica Cracoviensia. 2013;53(2):35-42.

45. Williams CA. Empathy and burnout in male and female helping professionals. Res Nurs Health. 1989;12(3):169-178.

46. Yuguero Torres O, Esquerda Areste M, Marsal Mora JR, Soler-Gonzalez J. Association between sick leave prescribing practices and physician burnout and empathy. PLoS One. 2015;10(7):e0133379.

47. Yuguero O, Marsal J, Esquerda M, Vivanco L, Soler-Gonzalez J. Association between low empathy and high burnout among primary care physicians and nurses in Lleida, Spain. Eur J Gen Pract. 2017;23(1):4-10.

48. Zenasni F, Boujut E, Woerner A, Sultan S. Burnout and empathy in primary care: three hypotheses. Br J Gen Pract. 2012;62(600):346-347.

49. Pines A, Aronson E, Kafry D. Burnout from Tedium to Personal Growth. New York: The Free Press; 1981.

50. LaMonica EL. Construct validity of an empathy instrument. Res Nurs Health. 1981;4:389-400.

51. Ganley RM. The Barrett-Lennard Relationship Inventory (BLRI): current and potential uses with family systems. Fam Process. 1989;28(1):107-115.

52. Meneghini A, Sartori R, Cunico L. Adattamento evalidazione su campione italiano della balanced emozionan empathy scale di Albert Mehrabian [Adaptation and validation on the Italian sample of balanced emotional empathy Albert Mehrabian Psychology Research]. Ric Psicol. 2006;29:123-152. Italian.

53. Balconi M, Canavesio Y. Emotional contagion and trait empathy in prosocial behavior in young people: the contribution of autonomic (facial feedback) and balanced emotional empathy scale (BEES) measures. $J$ Clin Exp Neuropsychol. 2013;35(1):41-48. 
54. Davis MH. Measuring individual differences in empathy: evidence for a multidimensional approach. J Pers Soc Psychol. 1983;44:113-123.

55. Hojat M, Gonnella J, Nasca T, Mangione S, Vergare M, Magee M. Physician empathy: definition, components, measurement, and relationship to gender and specialty. Am J Psychiatry. 2002;159:1563-1569.

56. Mehrabian A, Epstein N. A measure of emotional empathy. J Personal. 1972;40(4):525-543.

57. Barrett-Lennard G. The relationship inventory now: issues and advances in theory, method, and use. In: Greenberg LS, Pinsof WM, editors. The Psychotherapeutic Process: A Research Handbook. New York: Guildford Press; 1986:439-476.
58. Gleichgerrcht E, Decety J. Empathy in clinical practice: how individual dispositions, gender, and experience moderate empathic concern, burnout, and emotional distress in physicians. PLoS One. 2013;8(4): e61526.

59. Decety J, Yang C-Y, Cheng Y. Physicians down-regulate their pain empathy response: an event-related brain potential study. NeuroImage. 2010;50(4):1676-1682.
Psychology Research and Behavior Management

\section{Publish your work in this journal}

Psychology Research and Behavior Management is an international, peerreviewed, open access journal focusing on the science of psychology and its application in behavior management to develop improved outcomes in the clinical, educational, sports and business arenas. Specific topics covered in the journal include: Neuroscience, memory and decision making; Behavior
Submit your manuscript here: https://www.dovepress.com/psychology-research-and-behavior-management-journal

\section{Dovepress}

modification and management; Clinical applications; Business and sports performance management; Social and developmental studies; Animal studies. The manuscript management system is completely online and includes a very quick and fair peer-review system, which is all easy to use. Visit http://www. dovepress.com/testimonials.php to read real quotes from published authors. 